\title{
AN INTERRACIAL HYBRIDISATION EXPERIMENT IN NATURAL POPULATIONS OF DROSOPHILA WILLISTONI
}

\author{
A. R. CORDEIRO, F. M. SALZANO and V. B. MARQUES \\ Instituto de Ciêncios Naturais, Divisão de Genética, Universidade do Rio Grande do Sul \\ Pôrto Alegre, Brozil
}

Received 8.xii.59

As many as 66 different inversions evenly distributed in the five chromosomal arms are known in Drosophila willistoni, the most variable species of this genus so far studied in regard to this characteristic. Nevertheless, their frequency in natural populations varies greatly. In marginal populations, studied by Townsend (I952), da Cunha, Burla and Dobzhansky (1950), Dobzhansky (I957) and Cordeiro (1959), the $\mathrm{X}$ chromosomes are almost completely free of inversions. Also, the average number of inversions per individual decreases from the centre toward the edges of the species distribution. Interesting questions can be raised in connection with these findings. For instance, are these marginal populations able to accept heterotic gene arrangements of different origins? What will be the reaction of such populations to new gene orders from central populations?

Another aspect of interest is that Dobzhansky (1950), Dobzhansky and Pavlovsky (1953), and others, clearly showed that the equilibrium frequencies of heterozygous inversions are different if intra- or intergeographic population hybrids are used. The experimental study of inversion properties, on the other hand, was almost always made in artificial populations. Will the same principles apply to experiments performed under natural conditions?

This paper describes the results of cytologic analysis made during I 956 and 1957 of inversion frequencies in four semi-isolated natural populations of Drosophila willistoni. In three of them hybrids between populations of different geographic origin have been introduced.

\section{MATERIAL AND METHODS}

Some regions of Rio Grande do Sul, the southernmost State of Brazil, are covered by grassland, with scattered small woods isolated from each other by varying distances of hundreds of metres to several kilometres. Drosophila willistoni does not live in the grassland, building its semi-isolated populations in these true islands of woods, the "capões". This is the situation near the locality of Tainhas, in the Plateau of São Francisco de Paula's District, the place chosen for the experiment now reported.

Samples of more than one hundred individuals from Feliz, a locality near Tainhas, were crossed with northern Brazilian races, and the $F_{1}$ hybrids (North/South) cytologically analysed showed a high frequency of heterozygotes for inversions not observed in the natural populations of Feliz or Tainhas (table 1). A great number of $F_{1}(N / S)$ individuals was raised by daily transfer of 50 pairs in $1 / 4$ litre bottles with banana-agar-yeasted food. To avoid competition, extra amounts of yeast were distributed two days after the transfers. By counting five samples of 1000 individuals, an average weight was established for these $F_{1}(N / S)$ and, with the aid 


\begin{tabular}{|c|c|c|c|c|c|}
\hline \multirow{2}{*}{$\begin{array}{l}7 \\
\overrightarrow{8} \\
3 \\
3\end{array}$} & 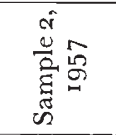 & 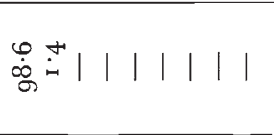 & $\stackrel{\circ}{\dot{g}} \dot{i}|\stackrel{+}{-}| 1 \mid$ & $\approx$ & 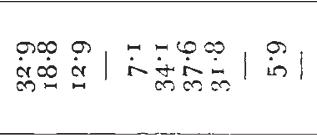 \\
\hline & 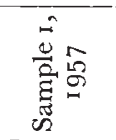 & $\stackrel{\circ}{\vdots}|1| 1|1| 1$ & $\stackrel{\circ}{\dot{g}}|1|||$ & $\bar{m}$ & 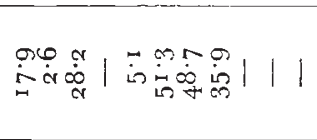 \\
\hline \multirow{2}{*}{$\begin{array}{l}z \\
z \\
8 \\
3\end{array}$} & 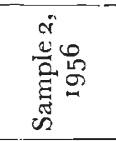 & $\dot{\dot{o}}|||||| \mid$ & $\dot{\vdots}|1| 1 \mid$ & $\stackrel{g}{\sim}$ & 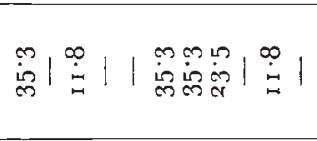 \\
\hline & 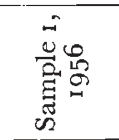 & 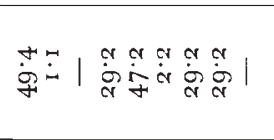 & 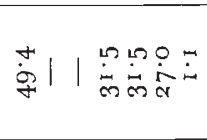 & $\infty$ & 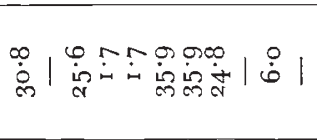 \\
\hline \multicolumn{2}{|c|}{ 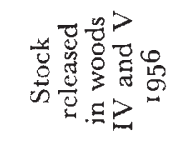 } & 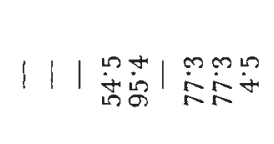 & ||$|\underset{\hat{q}}{\dot{\alpha} \hat{i}}|$ & वै & 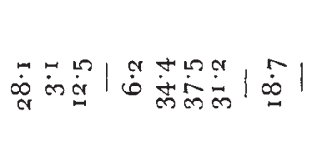 \\
\hline \multirow{4}{*}{$\begin{array}{l}7 \\
\overline{8} \\
3\end{array}$} & 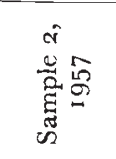 & 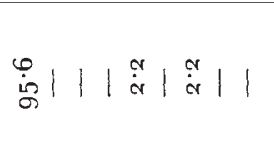 & 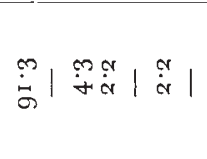 & $\mathscr{q}$ & 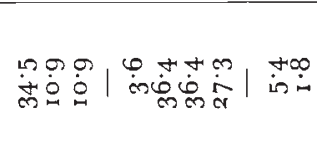 \\
\hline & 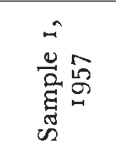 & 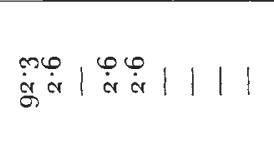 & 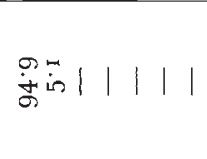 & मे & 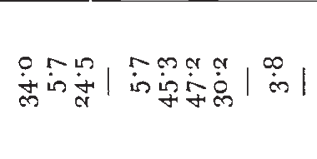 \\
\hline & 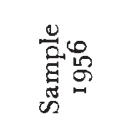 & 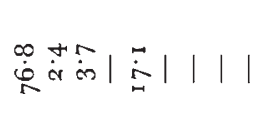 & $\dot{\infty}|||| \dot{\sigma} \mid$ & $\infty$ & 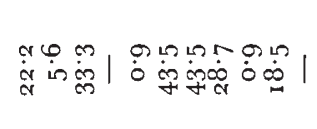 \\
\hline & 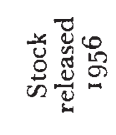 & $|1| 1 \stackrel{\circ}{\dot{0}}|1| 1$ & $|1||| \dot{\dot{g}} \mid$ & वे & 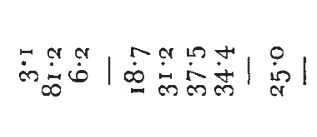 \\
\hline \multirow{2}{*}{$\begin{array}{l}\Xi \\
\Xi \\
0 \\
0 \\
0 \\
0 \\
0 \\
0 \\
0\end{array}$} & $\hat{\Omega}$ & $\stackrel{\circ}{\dot{\delta}}||||||||$ & $\stackrel{\circ}{\dot{g}}|||| \mid$ & 象 & 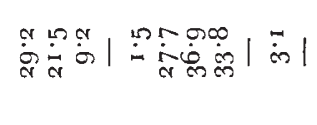 \\
\hline & 号 & $\dot{g} \dot{m}||||||$ & $\dot{\dot{g}}|| \overrightarrow{\text { m }}|\overrightarrow{\mid}|$ & రా & 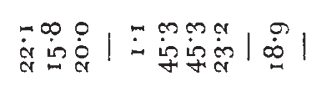 \\
\hline \multicolumn{2}{|c|}{ 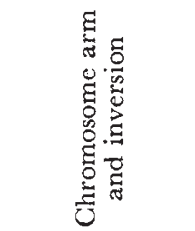 } & 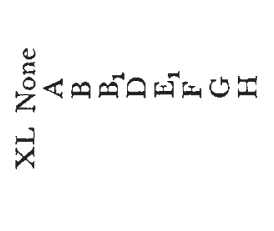 & 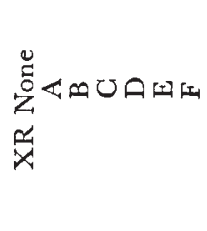 & 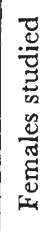 & 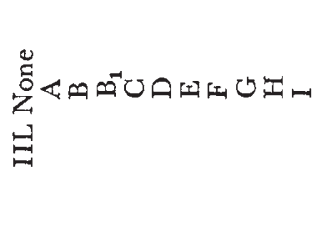 \\
\hline
\end{tabular}




\begin{tabular}{|c|c|c|c|c|c|}
\hline \multirow{2}{*}{$\begin{array}{l}7 \\
\overline{8} \\
8 \\
3\end{array}$} & 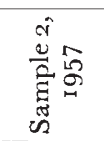 & 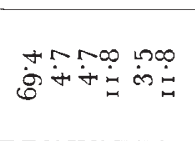 & 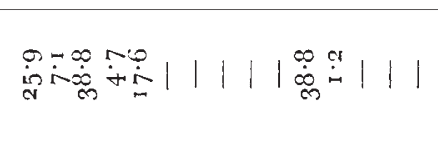 & $\infty$ & 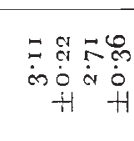 \\
\hline & 矛芯 & 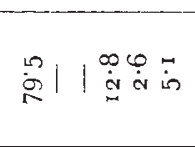 & क्ming & ले & 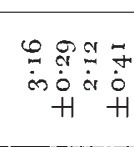 \\
\hline \multirow{2}{*}{$\begin{array}{l}2 \\
8 \\
8 \\
3\end{array}$} & 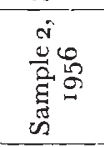 & 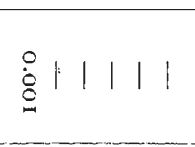 & 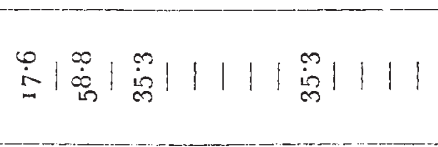 & $=$ & 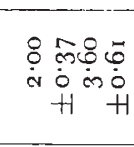 \\
\hline & 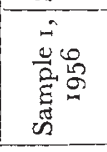 & $\dot{\phi}|+||| \stackrel{\varphi}{\dot{m}}$ & 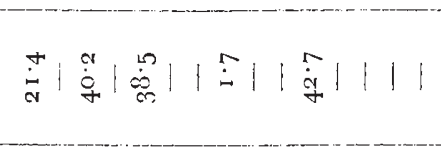 & $\equiv$ & 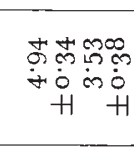 \\
\hline \multicolumn{2}{|c|}{ 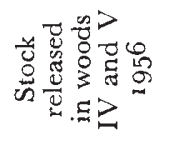 } & 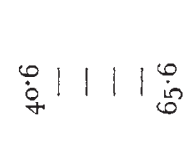 & 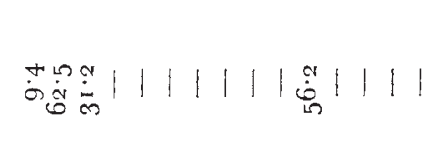 & कै & $\begin{array}{l}\infty \\
\infty \\
\infty \\
\infty\end{array}$ \\
\hline \multirow{4}{*}{$\begin{array}{l}7 \\
\overline{0} \\
\vdots \\
3\end{array}$} & 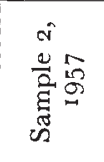 & 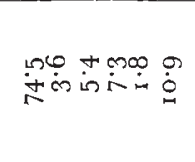 & 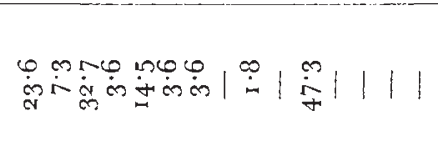 & in & 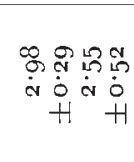 \\
\hline & 䒕命 & 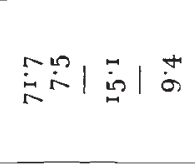 & 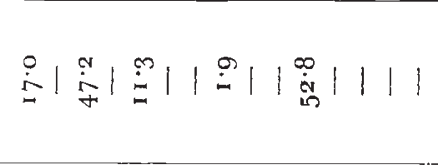 & กี & 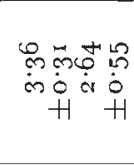 \\
\hline & 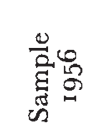 & $\stackrel{\infty}{i}|\dot{0}| \mid \dot{\dot{q}}$ & 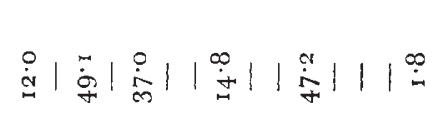 & $\stackrel{\infty}{\infty}$ & 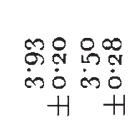 \\
\hline & 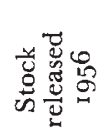 & $\dot{\sigma}|1| 1 \dot{8}$ & 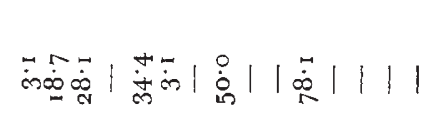 & జ్ & 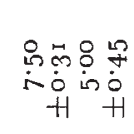 \\
\hline \multirow{2}{*}{ 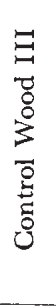 } & 呑 & 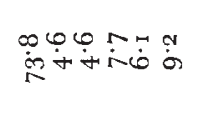 & 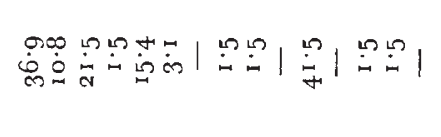 & 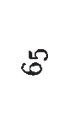 & 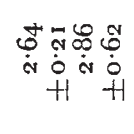 \\
\hline & 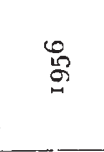 & $\stackrel{\varphi}{\dot{\delta}}|\vec{i}| \vec{i}$ & 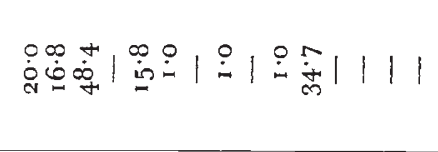 & 26 & 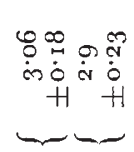 \\
\hline \multicolumn{2}{|c|}{ 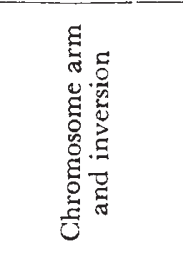 } & 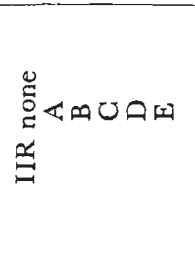 & 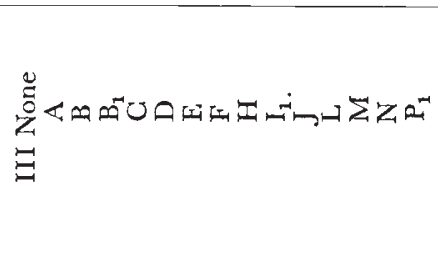 & 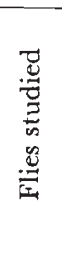 & 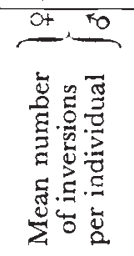 \\
\hline
\end{tabular}


of an analytical balance, the mass of $F_{1}(N / S)$ hybrid weighed was estimated to have contained about 180,000 individuals. Three isolated woods I, IV and V, previously chosen at Tainhas, received approximately 6o,ooo $F_{1}$ individuals each. The approximate distance between the control wood (III) and wood I is $7 \mathrm{~km}$.; between III and IV, $3 \mathrm{~km}$.; and between IV and V, $9 \mathrm{~km}$. Wood $\mathrm{I}$ is also isolated from the

TABLE 2

Significant differences between inversion frequencies of control samples of $\mathrm{D}$. willistoni

\begin{tabular}{|c|c|c|c|c|}
\hline $\begin{array}{c}\text { Chromosomes } \\
\text { and } \\
\text { inversions }\end{array}$ & \multicolumn{2}{|c|}{ Frequencies (per cent.) } & $\chi^{2}$ & $\begin{array}{c}\text { P } \\
\text { (I d.f.) }\end{array}$ \\
\cline { 2 - 4 } & 1956 & 1957 & & \\
\hline IIL-D & 45.3 & 27.7 & 5.05 & $<0.05$ \\
IIL-H & 18.9 & 3.1 & 8.88 & $<0.01$ \\
III-B & 48.4 & 21.5 & 11.90 & $<0.001$ \\
\hline
\end{tabular}

others by the Tainhas river. Near wood I ( $\mathrm{km}$. away) there is wood II, not studied in detail, but considered initially as a control to detect migration of the $F_{1}$ hybrid $\mathrm{N} / \mathrm{S}$ descendants.

Due to the cold winters, collections of Drosophila willistoni have been made in the summer seasons of 1956 and 1957 only. Cytologic analysis of the salivary glands were performed on single $F_{1}$ larvæ, produced by isolated cultures of one female each. The usual aceto-orcein technique was employed.

\section{THE ISOLATION OF THE POPULATIONS}

Some evidence may be given on the relative isolation of the populations studied. The $F_{1}$ hybrids were introduced in wood I at Io a.m. on February 6, I 956. The females were heterozygous for the recessive sex-linked mutant scute; half of the males were normal, and half carried scute as a marker. Intensive collections were made in wood II during all this day and in the next. The 4724 flies caught were classified in 17 different species, in the field laboratory, just after the collections. No scute male of $D$. willistoni was observed among the 344 individuals of this species collected (I 54 males).

The significance of this fact appears if we consider that in March Io and I I, I 956, in a total of 5455 flies collected at wood I, I 362 were of D. willistoni wild phenotype, plus 238 males and 57 females scute. The frequency of the scute gene was, thus, still very high : $q=0.2088$ for males and $q=0.3039$ for females. A few days after (March 23) wood II was visited and among 879 flies, collected with great difficulty due to the low temperature prevailing, I 8 were $D$. willistoni, wild type.

The I957 samples of wood I contained 2380 D. willistoni and no scute individual was observed. This was noted on the first collection of this year ; thus, no attempt was made to study the possible occurrence of this gene in wood II.

Another source of evidence about $D$. willistoni isolation in these woods was obtained by simple collecting experiments. In four different instances, 5 to 8 banana traps have been placed outside them, in a 
straight line from the edges toward the grassland (woods I and III). The occurrence of flies there was limited to the mornings (until Io a.m.) and $D$. willistoni was found in the first trap only.

The isolation is particularly strong during the winter season, despite the winds, because $D$. willistoni do not fly when the temperature is around $\mathrm{I} 3^{\circ} \mathrm{C}$ or lower. Consequently, the migration effect is negligible in the results we are going to describe now.

\section{CHROMOSOMAL POLYMORPHISM OF TAINHAS NATURAL POPULATIONS}

The absence, or rare occurrence, of inversions in the $\mathrm{X}$ chromosomes, and the relatively low average number of inversions per individual, characterises Tainhas and all other localities from Rio

TABLE 3

Significant differences of autosomal inversion frequencies between control and interracially hybridised natural populations of Drosophila willistoni

\begin{tabular}{|c|c|c|c|c|c|c|c|c|c|c|c|}
\hline \multirow{2}{*}{\multicolumn{3}{|c|}{$\begin{array}{c}\text { Chromosomes and } \\
\text { inversions }\end{array}$}} & & \multicolumn{2}{|c|}{$\begin{array}{c}\text { Control and } \\
\text { wood I, } \\
\text { sample in I956 }\end{array}$} & \multicolumn{2}{|c|}{$\begin{array}{c}\text { Control and } \\
\text { wood I, two } \\
\text { samples in } 1957\end{array}$} & \multicolumn{2}{|c|}{$\begin{array}{l}\text { Control and } \\
\text { wood IV, } \\
\text { sample in } 195^{6}\end{array}$} & \multicolumn{2}{|c|}{$\begin{array}{l}\text { Control and } \\
\text { wood V, two } \\
\text { samples in } 1957\end{array}$} \\
\hline & & & & $x^{2}$ & $\mathbf{P}(\mathbf{I}$ d.f. $)$ & $\chi^{2}$ & $\mathrm{P}(2$ d.f. $)$ & $\chi^{2}$ & $P(\mathrm{I}$ d.f. $)$ & $\chi^{2}$ & $P(2$ d.f. $)$ \\
\hline IIL-A & . & & & $5 \cdot 17$ & $<0.05$ & $6 \cdot 78$ & $<0.05$ & - & - & $7 \cdot 06$ & $<0.05$ \\
\hline IIL-B & . & . & . & $4 \cdot 55$ & $<0.05$ & $6 \cdot 34$ & $<0.05$ & - & - & $7 \cdot 38$ & $<0.05$ \\
\hline IIL-C & . & . & . & - & - & 14.99 & $<0.001$ & - & - & & - \\
\hline IIL-D & . & 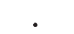 & 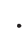 & - & - & - & - & - & - & 6.05 & $<0.05$ \\
\hline IIL-H & . & . & . & - & - & - & - & $8 \cdot 47$ & $<0 \cdot 01$ & - & - \\
\hline IIR-E & ${ }^{\circ}$ & . & & ${ }^{15} \cdot 84$ & $<0.001$ & $\overline{0.68}$ & - & - & 二 & $\overline{6 \cdot 06}$ & $<\overline{0.05}$ \\
\hline III-B & - & - & - & - & - & $8 \cdot 68$ & $<0.02$ & I & $\overline{-}$ & -20 & $<0.05$ \\
\hline $\begin{array}{l}\text { III-C } \\
\text { III-F }\end{array}$ & $:$ & : & : & $\begin{array}{l}\text { I 1 } 54 \\
\text { I } 2 \cdot 49\end{array}$ & $\begin{array}{l}<0.001 \\
<0.001\end{array}$ & - & - & 二 & - & - & 二 \\
\hline & & & & & & & & & & & \\
\hline
\end{tabular}

Grande do Sul to Argentina so far studied (Dobzhansky, I957 and Cordeiro, I959).

In the I956 control wood III sample some inversions occurred in the $\mathrm{X}$ chromosomes (XL-A, XR-G and XR-D); but they did not reappear in $\mathrm{I} 957$ (table $\mathrm{I}$ ). This fact is not significant however, due to the low frequency of these inversions in Tainhas. The same is true for several autosomal inversions, III-I $\mathrm{I}_{1}$ appearing in 1956 and not in 1957 and, inversely, III-B $, 3, \mathrm{M}$, and $\mathrm{N}$ occurring in 1957 and not in 1956 . Nevertheless, the absence in 1956 , followed by a relatively high frequency of inversions IIR-A and IIR-G in 1957 is probably significant. In the total of 26 different inversions recorded for either sample, only three showed significant $\chi^{2}$ divergency. All three decreased in frequency (tables I and 2).

Drosophila willistoni relative frequency increased from $3 \cdot 49 \pm 0 \cdot 36$ per cent. in 1956 to $64 \cdot 76 \pm \mathrm{I} \cdot 80$ per cent. in 1957 , in a total of $25^{\mathrm{I} 9}$ and 698 flies collected respectively. This increase is not apparently correlated with the observed changes in inversion frequencies. 
The composition of the inversions in Tainhas are in agreement, in a general way, with the data obtained by da Cunha, Burla and Dobzhansky (I950) and da Cunha and Dobzhansky (I954) for four localities of Rio Grande do Sul.

\section{THE COMPOSITION OF THE $F_{1}$ HYBRID NORTH/SOUTH STOCK RELEASED}

The stock released in wood I was heterozygous for two " new inversions" (XL-D and XR-E) as far as the populations of Tainhas are concerned (table $\mathrm{I}$ ), and the $\mathrm{X}$ chromosomes of females carried in single dose the visible mutant scute. The majority of the hybrids $\mathrm{N} / \mathrm{S}$ proved to be heterozygous for these two new inversions, and carried high frequencies of the autosomal inversions IIL-A, IIR-E, III-C, III-F and III-J. The average number of inversions per female, $7 \cdot 5^{0} \pm 0.31$, were more than double in comparison with the control populations. Two other releases were made, in woods IV and V. The composition of this stock included a visible autosomal mutant gene ebony in heterozygous condition and high frequencies (see table $\mathrm{I}$ ) of the "new" inversions XL-B, XL-D, XL-F and XL-G. The inversions XR-C and XR-D, also present in high numbers, had already been found in the control population in 1956 , though with lower frequencies. No increase in the inversion content of the left arm of the second chromosome was observed in relation to the Tainhas natural populations, but the stock released carried as much as $6_{5} \cdot 6$ per cent. of IIR-E, a common inversion in the northern races but relatively less frequent in southern populations (Dobzhansky, I957). The III chromosome presented a great increment of the $\mathrm{A}$ and $\mathrm{J}$ inversions. The mean number of inversions per individual female was even higher than in the scute bearing stock, i.e., $8 \cdot 36 \pm 0 \cdot 4 \mathrm{I}$.

\section{THE SHIFT FROM BALANCE PRODUCED IN THE TAINHAS NATURAL POPULATION}

The N/S stock released at the isolated wood I and wood IV, produced a temporary shift from balance, changing significantly the inversion frequencies during 1956. The results obtained can be seen in tables I and 3. The first sample in wood I was made 23 days (about 2 generations) after the release of the hybrid N/S flies. The frequency of $D$. willistoni in the total of flies collected then (5 160 individuals) was $30 \cdot 4 \pm 0 \cdot 6$ I per cent., as compared to $4 \cdot 3 \pm \mathrm{I} \cdot 7$ per cent. found before the release. This increase occurred also in the control wood.

The "new" X chromosome inversions introduced in wood I were XL-D and XR-E. They appeared in fairly high frequencies in I956, decreasing to low levels in I957 (table I); however they were not lost after the ${ }_{195} 6$ winter. Inversion XL-F did not appear in the stock released, or in the 1956 sample, but was present in the 1957 second 
sample at the low frequency of $2 \cdot 2$ per cent. This inversion probably was present at a low frequency in the released stock and in the other samples. The " new" inversions released in woods IV and V (table I) appeared only in the first 1956 sample. The second 1956 sample was too small to be significant, but the two I957 samples, with I02 individuals analysed, confirmed the absence or extreme rarity of these inversions.

Several other inversions, present at very high frequencies in the hybrid North/South $F_{1}$, and occurring at Tainhas in lower frequencies, showed an increase, followed by a decrease and return to the control wood III level. Some cases should be emphasised. The comparison between the control wood III samples of $195^{6}$ and 1957 , mentioned before, disclosed a significant decrease of IIL-D, IIL-H, and III-B (table 2). On the other hand, the comparison between the controls with the experimental woods' samples showed a very different picture. In wood I the significant decrease of IIL-A (1956-I957) was opposed by an increase in frequency of IIL-B (1956-1957); IIL-C (I957); IIR-E ( 1956 ) and III-C ( 1956 ). Inversion III-F increased in frequency in $195^{6}$ and declined in 1957 ; and finally III-B was present in high frequency in the first sample of 1957 and dropped down in the 2nd sample (see table 3 ).

Woods IV and V presented a similar picture. The only significant contrast in wood IV, however, is the 1956 decrease in frequency of IIL-H compared with the control wood III in 1956 (table 3 ). This inversion was not detected in the first sample of wood V in 1957 and was found in 5.9 per cent. of the second sample (table I). This frequency is significantly lower than that found in wood IV in $195^{6 .}$ IIR-E, which is common in northern populations, had its frequency raised after the release in wood IV in $195^{6}$, but was reduced to control values in wood $\mathrm{V}$ in 1957. The same can be said of inversions III- $\mathrm{C}$ and III-J (table I).

There are significant $\chi^{2}$ differences among the inversion frequencies of the three after the release samples of wood I, contrasting with more uniformity in woods IV and V. Thus, in wood I, after the initial rise in frequency, there were significant decreases in the occurrence of inversions XL-D, XR-E, IIL-B, IIL-H, IIR-E, and III-C. In woods IV and V, IIR-E and III-C presented also a significant decrease, while the two samples of wood $\mathrm{V}$ were significantly different in regard to the frequency of IIL-B.

Several differences were noted between the r 957 wood V samples and the control of the same year (table 3 ); but because no sample of this wood was collected in 1956 , and some significant differences were found also between the controls, no clear conclusion can be drawn from them.

The first samples after the release of the hybrids in woods I and IV showed a significant increase in the mean number of heterozygous inversions per individual female (table $\mathrm{I}$ ). However, a recurrence to 
control levels was observed in I957. The number of males studied was too small to disclose significant differences.

\section{DISCUSSION}

The comparisons made by Dobzhansky and Wright (1947) shows that $D$. pseudoobscura has the same dispersion rate as $D$. funebris, studied by Dubinin and Tiniakov (1946). On the other hand, D. willistoni has a significantly lower dispersion rate, when compared with $D$. pseudoobscura, according to Burla et al. (1950). This is important to consider in connection with the results reported here. The isolation among the woods' populations of Tainhas is an important condition, satisfied in our experiments.

Dubinin and Tiniakov (1946) reported an experiment in some points similar to ours. They gave some indirect evidences about the isolation of the Kropotovo population of $D$. funebris, which received I oo, ooo individuals homozygous for the II-I inversion. The frequency of the individuals homozygous for this inversion increased one month after the release and decreased rapidly from July to October. The heterozygote increment occurred at the expense of both homozygous II-I inversion and standard. The last arrangement was predominant before the release. Natural selection favoured the heterozygotes, according to Dubinin and Tiniakov (1946). Why it had not favoured them before, they did not try to explain. The trend toward the elimination of the homozygotes II-I was very strong, and it is not clear if stabilisation of the inversion frequencies occurred at the end of the experiment. This may suggest that the final results consisted in a return to the former composition of the original population.

Five of the seven northern population inversions introduced in three semi-isolated southern natural populations of Drosophila willistoni have been lost, one year after the release. XR-E, lost in woods IV and $\mathrm{V}$, remained in wood $\mathrm{I}$. The fact that the majority of the inversions did not survive in the populations conforms with the concept that they have adaptive functions. The frequencies of $D$. willistoni inversions are correlated with ecologic opportunities, according to da Cunha, Burla and Dobzhansky (I950), and da Cunha and Dobzhansky (I954). XL-D, retained at Tainhas, was one of the heterotic sex-linked inversions studied by da Cunha (1955) in population cages. This inversion has been observed by da Cunha and Dobzhansky (I954) in Melo, Uruguay, although it has not been detected at the Tainhas control populations.

The rejection of northern gene arrangements suggests that inversions cannot be used as markers to determine the probable centre of origin of the species, as proposed by da Cunha, Burla and Dobzhansky (I950). Vavilov ( I 926) correctly based his hypothesis about centres of origins on the relative amount of adaptively neutral traits, which accumulates with time. 
Turning now to inversions IIR-E and III-J, studied by Dobzhansky and Pavlovsky ( 1958 ) in experimental populations of Drosophila willistoni from the Brazilian localities of Recife and Guaramiranga, we may recall that in our experiment the release in $195^{6}$ raised the IIR-E frequencies to about 20 and 30 per cent., respectively, from the control value, these frequencies returning to normal levels again in 1957. The occurrence of III-J was not affected by the release. The results of Dobzhansky and Pavlovsky (1958), on the other hand, showed a clear significant loss of heterozygosity of the reciprocal hybrid populations Guaramiranga/Recife and Recife/Guaramiranga. The interpretation we propose for these apparently conflicting results is the following: the racial hybridisation produced, in both experimental and natural populations, a breakdown of coadapted gene complexes. However, due to the degree of environmental diversity, the natural population of Tainhas retained its characteristic amount of polymorphism. Contrasting with this, the stabilising selection active on experimental cage populations reduced the racial mixture to a more homogeneous population, more likely to be fit in the more constant and simpler cage conditions (Thoday, r959; Lewontin, r958).

The stability observed by Dobzhansky and Pavlovsky (1958) in the experimental cages with the "pure" racial stock of Recife or Guaramiranga, on the other hand, suggests that a balanced population tends to maintain its structure even when transferred from its original heterogeneous environment to a more homogeneous one. Many experimental attempts to remove populations rapidly from " adapted average values for specific traits, either by artificial selection or by changes in the breeding system, are counteracted by natural selection, which is directed towards the maintenance of a phenotypic balance between fitness determining characters" (Lerner, I 954). The Tainhas experiment may be described as an attempt to increase heterozygosity; this has been counteracted by natural selection, also.

\section{SUMMARY}

I. An experimental introduction of about 60 , ooo $\mathrm{F}_{1}$ hybrids of North/South races of Drosophila willistoni was performed in three isolated small woods at the grassland region of Tainhas, Rio Grande do Sul, Brazil.

2. Cytologic analysis of polytenic salivary gland chromosomes of the $F_{1}$ North/South hybrids showed a very high frequency of six " new" inversions in the $\mathrm{X}$ chromosome, not present at the Tainhas region (XL-B $1, X L-D, X L-F, X L-G, X L-H$ and XR-E), and more than 5o per cent. of inversions XR-G, XR-D, IIL-A, IIR-E, III-A and III-J.

3. The first sample after the release of the $\mathrm{N} / \mathrm{S} \mathrm{F}_{1}$ hybrids, showed a relatively high frequency of the "new" $\mathrm{X}$ chromosome inversions introduced and a significant increase of some autosomal inversions. 
4. The samples of the following year disclosed an opposite situation, since most of the introduced genetic novelties have been lost or decreased at too low frequencies to be detected. The only surviving " new" inversions were in one of the three woods studied (wood I, inversions XL-D and XR-E).

5. The autosomal inversions that increased in frequency after the release of the hybrids, dropped down to the control level of frequencies one year after.

6. The average number of heterozygous inversions per individual presented a similar increase and return to normal values.

7. Several conclusions can be drawn from this experiment. First we may say that a shift from balance was produced in the frequency of heterozygous inversions. Second, that the genetic structure of outbreeding natural populations has strong homeostatic properties, that tend to reject abrupt or drastic changes even if these are for a further increase in heterozygosity. Third, that the differences observed between natural and experimental interracial hybridisation experiments showed the importance of environmental variability in the origin of genetic polymorphism.

Acknowledgments.-- This work has been supported in part by grants of the Conselho Nacional de Pesquisas and the Rockefeller Foundation. We are deeply indebted to Professor Theodosius Dobzhansky for suggesting this work and helping in the search for the isolated woods in January $195^{6}$ at the Tainhas region. Part of the salivary gland slides have been made by Mr Jorge Petersen.

\section{REFERENCES}

BURla, H., DA GUNha, A. B., CAVAlGanti, A. G. L., Dobzhansky, TH., AND PAVAN, C. 1950. Population density and dispersal rates in Brazilian Drosophila willistoni. Ecology, 31, 393-404.

CORDEIRO, A. R. I959. Chromosomal variations in Drosophila willistoni from Rio Grande do Sul (Brazil) (unpublished).

DA GUNHA, A. B. 1955. Differential viability favouring inversion heterozygotes in Drosophila willistoni. Evolution, Io, 231-234.

DA CUNHA, A. B., AND DOBZhansky, TH. I954. A further study of chromosomal polymorphism of Drosophila willistoni in its relation to the environment. Evolution, 8, I I 9 -I 34 .

DA CUNhA, A. B., BURla, H., AND DOBZhaNSKy, TH. I950. Adaptive chromosomal polymorphism in Drosophila willistoni. Evolution, 4, 2 I 2-235.

DobZhansky, тH. I950. Genetics of Natural Populations. XIX. Origin of heterosis through natural selection in populations of Drosophila pseudoobscura. Genetics, 35, 288-302.

Dobzhansky, тH. I957. Genetics of Natural Populations. XXVI. Chromosomal variability in island and continental populations of Drosophila willistoni from Central America and the West Indies. Evolution, II, 280-293.

DOBZHANSKY, TH., AND PAVLOVSKY, O. I953. Indeterminate outcome of certain experiments on Drosophila populations. Evolution, 7, I 98-210.

DOBZHANSKY, TH., AND PAVLOVSKY, O. 1958. Interracial hybridization and breakdown of coadapted gene complexes in Drosophila willistoni. P.N.A.Sc., 44, $622-629$. 
DobZhansky, TH., AND Wright, s. 1947. Genetics of Natural Populations. XV. Rate of diffusion of a mutant gene through a population of Drosophila pseudoobscura. Genetics, 32, 303-324.

DUBININ, N. P., AND TINIAKOV, G. G. I 1946 . Inversion gradients and natural selection in ecological races of Drosophila funebris. Genetics, $3 I, 537-545$.

LERner, I. M. I954. Genetic Homeostasis. John Wiley and Sons, New York.

LEWONTIN, R. C. I958. Studies on Heterozygosity and Homeostasis. II. Loss of heterosis in a constant environment. Evolution, 12, 494-503.

THODAY, J. M. I959. Effects of disruptive selection. I. Genetic flexibility. Heredity, 13, I87-203.

TOWNSEND, J. I. I952. Genetics of marginal populations of Drosophila willistoni. Evolution, 6, 428-442.

vavilov, N. I. I926. Studies on the origin of cultivated plants. Leningrad. 